\title{
Audience Development in Thai Contemporary Theatre and Dance: A Study of the Barriers to Audience-Building
}

\author{
Piyawat Thamkulangkool \\ Lecturer, Department of Dramatic Arts, Faculty of Arts, Chulalongkorn \\ University, Bangkok, Thailand \\ thpiyawat@yahoo.com
}

\begin{abstract}
This research article examines the current situation of audiences in Thailand who attend non-mainstream contemporary theatre and dance, focusing on the barriers to building audiences for this type of performance. Mixed methods were used to collect data from various target groups, including qualitative methods like in-depth interviews, and focus groups for contemporary theatre and dance companies and arts spaces, and quantitative data gathered from audience questionnaires and surveys. The study revealed that many theatre and dance companies or groups run by artists often put more emphasis on their performance-making than on their organization or management. Such a production-centered emphasis often neglects the importance of two-way interaction between artists and audiences and shows insufficient appreciation of audiences in developing their performances and programs. The inattention of many performance companies or groups to their current and potential audiences and to techniques to build and develop them is widespread, but not universal. However, a few groups have worked to create and manage their performances based on audiences' perspectives, thus both removing barriers to performance participation as much as possible and motivating transactional relations with audiences. Audience responses from these companies has led to greater audience engagement and improved audience appreciation.
\end{abstract}




\section{Keywords}

audience development - audience building - contemporary theatre / dance audiences - performing arts management - theatre audience

\section{Introduction}

Few people in Thailand have systematically tried to understand audience development concepts or practices. Instead, many artists, non-mainstream theatre or dance companies and academics have focused on the model of "audience education". Thus, it is common to see clichés like "We need to develop our audiences; they have to be educated in arts appreciation!" in the Bangkok theatre community, especially when few people attend productions. Performance groups often interpret the feedback from their productions as signs that audiences often do not understand their performance or do not appreciate their work. Audience education is surely one important part of audience development, but it is not enough. Emphasizing this aspect exclusively has likely led to small audiences and financial losses for some theatre productions. Is there some way of improving this situation?

Since around 2010, many new non-mainstream contemporary art spaces have been established in Thailand, especially in Bangkok, as seen in Democrazy Theatre Studio (2009), Creative Industries (2014), Bangkok City City Gallery (2015), Thonglor Art Space (2015), Syrup the space (2015), (Thailand 2014). These spaces have provided diverse, cutting-edge and experimental arts programs and interdisciplinary activities, including domestic productions and international collaborative projects produced by veteran and new artists. The art spaces have played an important role in shaping Bangkok's contemporary performing arts scene.

Despite the greater number of art spaces and theatre companies in Bangkok, however, some evidence suggests that audiences have not grown to match the greater supply of spaces. On June 27, 2018, Pawit Mahasarinand, then Director of Bangkok Art and Culture Center (BACC), indicated that after more than 20 years of being a theatre critic, the number of theatre goers, especially at small scale non-profit theatres in Bangkok, had not changed much. He noted that when he goes to many theatre events, he often meets the same audiences, and that they are also often artists or staff working with other theatre groups. He suggested that even if this shows a committed theatre community whose numbers may have expanded somewhat, they have done so only slowly. Such a situation made him wonder: "Where are the new audiences?" 
The government has not done much to support audience building, either. The website of Office of Contemporary Arts and Culture (OCAC) of the Ministry of Culture of Thailand has a research database showing 68 research projects conducted with support of the OCAC between 2006 and 2017, but only one project was tied to an arts audience issue. It focused on the trends and factors that influence the aesthetic experience of audiences in contemporary art and cultural centers. The website database of the Department of Cultural Promotion of the Ministry of Culture of Thailand includes goo research projects from all over country sponsored by the Department, but none addressed any audience-related topic.

Academic work in this area is also thin. One important collection of essays about Thai arts audiences, "kan rap kan sep kan boriphok ngan sinlapa" [Arts Reception, Appreciation, Consumption] included essays by researchers in literature, visual arts, music and performing arts, and was a product of the research project "Criticism as an Intellectual Force in Contemporary Society" run by Dr. Chetana Nagavajara and his research team under the aegis of the Thailand Research Fund (TRF). The volume grew from the annual meeting in Humanities at the Princess Maha Chakri Sirindhorn Anthopology Centre on March 30, 2006. (Kamsorn 2006).

Although there are many studies and research on audience development or audience building in western countries, Thailand has produced few, showing that this topic is not yet considered important or relevant. This research project aims to understand the current situation of non-mainstream contemporary performing arts audiences in Thailand by identifying the key barriers of building or increasing Thai contemporary performing arts audiences. This will become a steppingstone to establishing an academic basis in Thailand for research in arts audience development. It further aims to encourage more study in the field.

Toward those ends, this article will be structured as follows. First, a review of literature on audience building and development provides insights into and value of the concept of audience development. This review will also suggest a theoretical framework for use in this study. Following a description of the methodology used for this research, the findings are presented. The impact of the study is finally discussed in a short conclusion.

\section{A Brief Look at the Concepts of Audience Building and Audience Development}

Audience development in the arts is rooted in the idea of making arts more accessible to people. One approach to this goal has viewed arts audiences as 
customers involved in transactions with an artist or an arts organization, and has thus stressed marketing as fundamental to developing audiences. Hill has noted that "[i]n practice, this means that the main task of arts marketing is to motivate people to attend performances and exhibitions or purchase art works or crafts, encouraging them to share in the artistic experience being provided. To do this effectively, arts organizations must understand the needs, desires and motivations of all those people who are, or could be, attenders at their events or venues" (Hill et al., 2003, 36). Those using a broad perspective view audience development as actions aiming to help arts organizations develop durable relationships with current and potential audiences that can meet audience needs. (Mcintyre 2009, 12). When developing audiences has been tied to socio-economic development, it seeks to use artistic and cultural activities to promote non-artistic goals, and to produce greater artistic or cultural participation, by extending access to those who consume and those who participate in artistic and cultural production. In all cases, audience development requires an audience-centered mindset, since it affords a more open-minded, inclusive and strategic audience building approach that can help make arts and culture more accessible to more people (Bamford and Wimmer 2012, 9).

In developing an audience-focused approach that provides audiences access to the arts, it is crucial to understand the obstacles that keep people from participating in the arts, so they can be overcome. Besides requiring substantial planning, audience-centered approaches also seek to broaden and enrich individuals' experiences of the arts (Maitland 2000). Such a comprehensive perspective is central to the Arts Council England's definition of audience development as "activity to help develop relationships with new and existing audiences. It can include aspects of marketing, commissioning, programming, involvement in decision making, education, customer care, and distribution" (Arts Council England 2018, 3). To realize such goals requires systemic thinking and planning of effective activities that will involve audiences in artistic processes in three main areas: educational work, marketing efforts, and artistic functions. This is summed up in the schematic "formula" of audience development below:

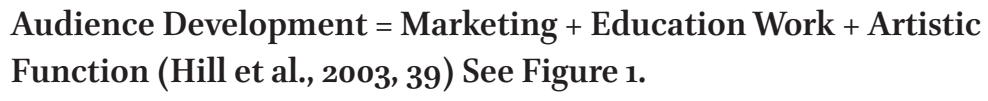

Education work is key to the above approach and widely practiced, normally by focusing on the long-term development of an individual's appreciation of the arts. These efforts usually aim to create an "audience of tomorrow" rather 


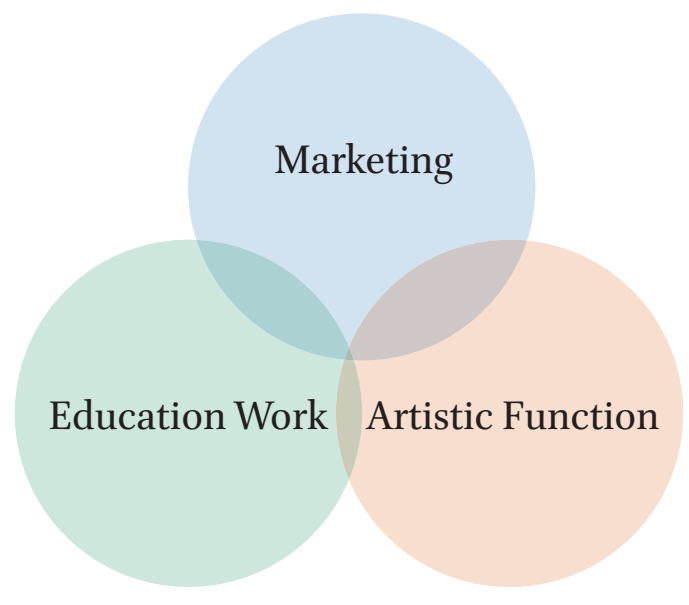

FIGURE 1 Audience development is a collaboration between the marketing, education work and artistic functions (From Hill, et al. 2003, 39).

than active arts attenders today. Participatory activities with small groups is commonly used here, with a view to provide them with experiences that will help change their attitudes toward and understandings of artistic work.

Marketing is likewise one of the three key approaches that arts organizations need to consider in developing their audience base. Marketing activities can engage audiences, help strengthen relationships, and generate valuable links between audiences and arts organizations.

Artists likewise are of course crucial to the audience development process by creating work that can be accessed by their target audiences. It is important for artists to find the appropriate formula for creating work that can both appeal to and challenge audiences and the artists themselves.

While artistic groups may realize the importance three above dimensions of audience development, many of them often neglect or even ignore the long-term planning required to generate and implement an audiencecentered approach to the arts. Walmsley $(2011,9)$ has noted how "[a]udience development is often seen as a challenging task that is under-estimated and under-resourced, and regarded as a cost rather than an investment. Worse, it is sometimes even regarded as a set of short-term publicity tactics rather than a long-term strategy to achieve fundamental artistic, financial or social objectives." Artistic organizations in Europe continue to debate the relative value of viewing the art-audience relationship as one best framed around the notion of cultural consumption, cultural education, or cultural participation (Bollo et al., 2017). They see the "audience as customer" notion as dangerous, since 
it could diminish the social or cultural value of arts and lower the position of artists in society and culture. (Bamford and Wimmer 2012, 10).

\section{$4 \quad$ Research Objectives, Questions and Assumption}

Based on the above review of existing studies into audience building and development, this research seeks to understand the current situation of non-mainstream contemporary performing arts audiences in Thailand, especially to identify the key barriers of building or increasing Thai contemporary performing arts audiences. This research will also help establish an academic basis in Thailand for research in arts audiences which will encourage further study in the field.

This study specifically seeks to address the following research questions:

I. What are the main factors of audiences affecting their decisions about whether to attend a performance?

II. What are the key constraints on building or increasing the audiences for theatre and dance organizations?"

The following hypothesis rises from these research questions:

- Since artist-audience relations do not currently work interactively in contemporary Thai theatre and dance, better communication and understanding between artists and audiences should be developed between them so they work as a two-way street. (See Figure 2.)
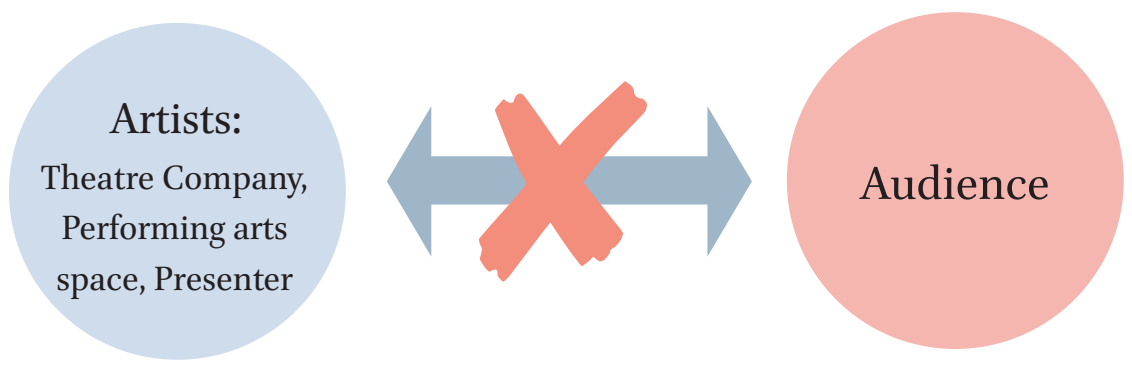

FIGURE 2 Author's schematic figure showing the lack of interactive two-way connections between contemporary performing arts groups and organizations and audiences in Thailand.

The research for this article is based on mixed methods, using both quantitative and qualitative approaches. The specific method of data collection differed depending on each target group. It included document analysis, 
in-depth interviews and focus groups with artists, and survey questionnaires with potential audiences from different age groups. The quantitative methodology was designed to discover the views of random audience members and to answer the first research question. The use of qualitative methods gathered artists' responses to address the second research question.

Criteria for selecting interview subjects for the qualitative methods emphasized non-mainstream performing arts organizations, specifically contemporary theatre and dance groups or companies, arts spaces, producers and independent theatre makers or dancers based in Bangkok or outside it. In-depth interviews were used to collect data from those who ran art spaces, independent producers of dancers, and theatre and dance groups or companies that have been running more than four years and which have created more than two productions per year in that time. Focus group participants were chosen from newer theatre companies that have been running less than four years who created more than two productions per year.

\subsection{Quantitative Approach (May-June 2018): Data came from 325 Audience Members who Handed in Questionnaires and Surveys at Two Random Venues as Follows}

I. Bangkok International Children Theatre Festival 2018, two performances of "Gabez Show (Japan)" \& "Sarabande (France)" at the Sodsai Pantoomkomol Centre for Dramatic Arts, Bangkok (24-27 May 2018)

II. "Rx3" by LIFE Theatre at Bluebox, M Theatre (1-13 June 2018) The survey questionnaire used for the above consisted of two sections. The first section sought general information from the participants, while the second section asked five questions about why the respondents participated in arts events, as follows:

1. How often have you come to watch a contemporary performance?

2. What kind of contemporary performance would you choose?

3. What are the main factors that make you decide to watch the performance?

4. What are the key factors that make you decide not to watch the performance?

5. What are your expectations from watching a performance?

5.2 Qualitative Approach for Collecting Data from Artists (June August 2018)

I. In-depth interviews of 27 professional representatives, as follows: Four non-mainstream art spaces in Bangkok:

Bangkok Art and Cultural Center: BACc, Democrazy Theatre Studio, Thonglor Arts Space, Creative Industries 
Five non-mainstream art spaces outside Bangkok:

Vic Hua Hin (Prachuabkirikhan), Ban Lakhon Yimnoi Yimyai (Uttaradit), Mor Lum Hun Theatre space (Mahasarakham), Hong Hiean Suebsan Poompanya Lanna (Chiang Mai), KAD Performing Arts School (Chiang Mai)

Twelve theatre and dance groups/companies that existed for more than four years and which staged non-mainstream performances in Bangkok, averaging more than two productions per year:

Crescent Moon Theatre, B-Floor Theatre, Naked Masked Theatre Network, 8x8 Theatre Group, Pichet Klunchun Dance Company, Anatta Theatre Group \& Bangkok Theatre Network, The Art and Cultural Institute for Development (Maya), Babymime, 18 Monkeys Dance Company \& Unfolding Kafka Festival, New Theatre Society, Khantha Arts Group, LIFE Theatre

Three theatre groups or companies that have existed more than four years and staged non-mainstream performances outside Bangkok:

Handmade Puppet (Chiang Mai), Wandering Moon Theatre (Chiang Mai), Makhampom Chiang Dao (Chiang Mai)

Two Independent contemporary Lanna dancers

One Independent producer

II. Two focus groups of eight representatives from seven young-generation theatre companies that have been running less than four years with the average of at least two productions per year:

Splashing Theatre (1 representative), For What Theatre (1 representative), A Theatre unit (1 representative), Fullfat Theatre ( 2 representatives), Miss Theatre ( 1 representative), Scarlette Theatre (1 representative), BIPAM/ For What Theatre/B-Floor (1 representative)

The process used in each focus group started with a warmup session which involved watching some video clips of case studies on audience-building in different countries and then had those in the focus group brainstorm on the point of view presented in each video clip shown. The discussion then moved to consider several topics, focusing on each participant's own experiences of 
theatre-making, including how that particular company or group created a performance, how the group produced its productions and managed costs and income, and then went on to discuss their attitudes to making performances for their audiences.

\section{6}

\section{Findings}

This section presents the key findings from the above data gathered from audiences and artists.

\subsection{Audience Voices \\ 6.1.1 General Information about Audiences}

From the questionnaires, the audiences consisted of $64 \%$ women, $31.7 \%$ men, and $4.3 \%$ of other genders. The ages of a large majority (66\%) were between 20 and 39 years old, and their main occupations were overwhelmingly professional workers $(67 \%)$ or students $(26 \%)$. As to the sources of information about performances, half of the surveyed audiences learn from online media platforms, with $10 \%$ of them learning from traditional mass media (TV, radio, magazines, and newspapers), and a similar number (11\%) gaining information from ephemera (posters, playbills, leaflets, etc.).

In terms of how frequently they attended performances, more than half of the audience responded with "Not sure", followed by $16 \%$ responding, "First time experience" or "Once a month watching." Only $12 \%$ of them said they watched live performances " $3-5$ times a month." As to the type of live contemporary live performances that audiences preferred, large majorities preferred stage plays/spoken-word plays (77.5\%), musicals $(65.10 \%)$ and concerts/music performances $(64.80 \%)$, with audiences who preferred mime, performance art, contemporary dance, standup comedy and puppetry at nearly the same percentage of $30-40 \%$.

\subsubsection{What are the Main Factors Affecting your Decision to Attend Live Performances?}

The top five responses to this question were topped by the "Show is interesting $(18.8 \%)$ ", followed by similar levels for having "free time available (13.3\%)", the show having a "reasonable ticket price (12.2\%)", "support the artist (11.7\%)" and "renowned performance/artists (11.3\%)". Audiences also referred to convenience issues, such as "public transport accessible location (7.2\%)", "parking lot availability (4.6\%)" and "easy ticket buying procedure (3.5\%)". (See Figure 3 for details.) 


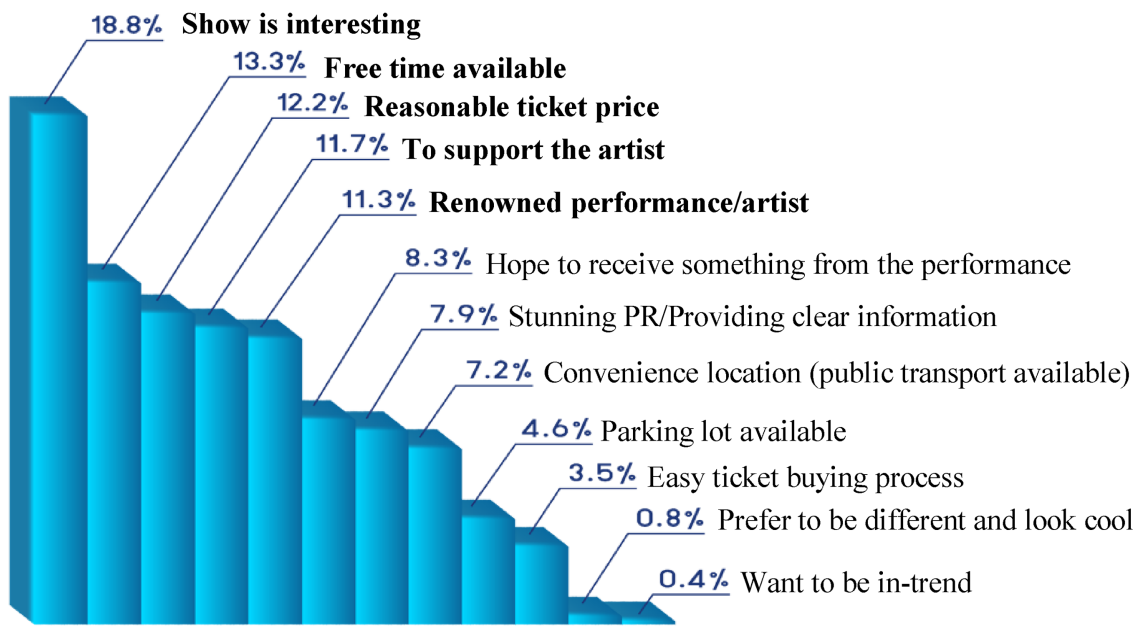

FIGURE 3 The main factors affecting audience decisions to attend performances.

6.1 .3

What are the Key Factors Affecting your Decision to not Attend Performances?

The top five factors given for why audiences chose not to attend performances were the following: no available time $(15.6 \%)$, expensive ticket prices, performance not worth the ticket price (12.7\%), remote locations/ inconvenient transportation (10.9\%), receiving information about the performance too late, unable to plan (9.3\%) and unattractive PR (9.2\%) (See Figure 4). These five factors contribute most to discouraging audiences from attending the performance. Although most audience members said that "no available time" was the key reason keeping them from performances, the findings also show that four of the five main obstacles stem from the arts organizations.

\subsubsection{What are your Expectations from Watching the Performance?}

From the audience survey data, it can be seen that audiences expect to receive some psychological benefit $(26.6 \%)$ from joining arts events since they are "able to spend a good time appreciating arts," and that joining a performance is a type of "self-fulfillment $(23.2 \%)$ " where they can "laugh, cry and release their emotions" (13.8\%) while appreciating the performance (See Figure 5). In addition, they mention educational benefits like "being able to learn new experience or knowledge from the performance" $(25.8 \%)$ and social purposes like "being able to spend time with friends" and having "a chance to meet new people/society". 


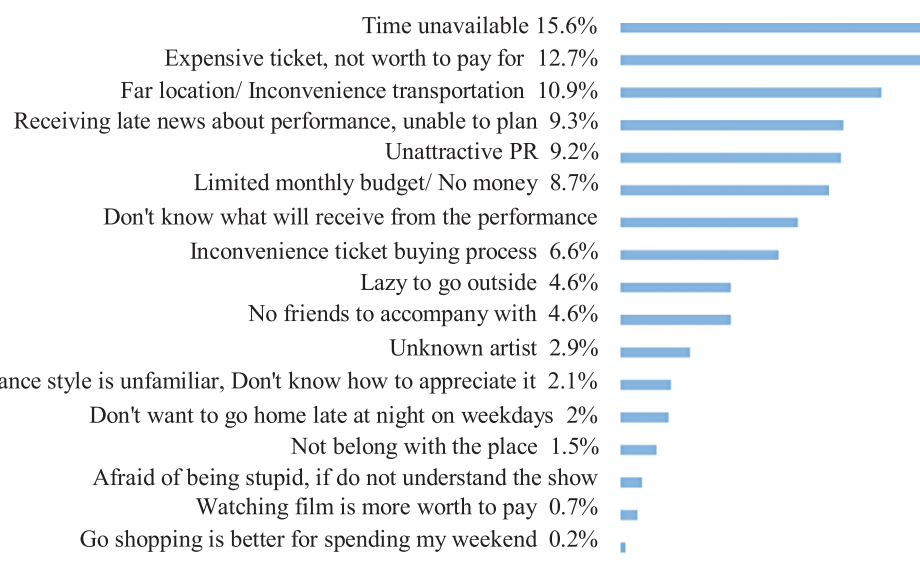

FIGURE 4 The main factors affecting audience decisions not to attend performances

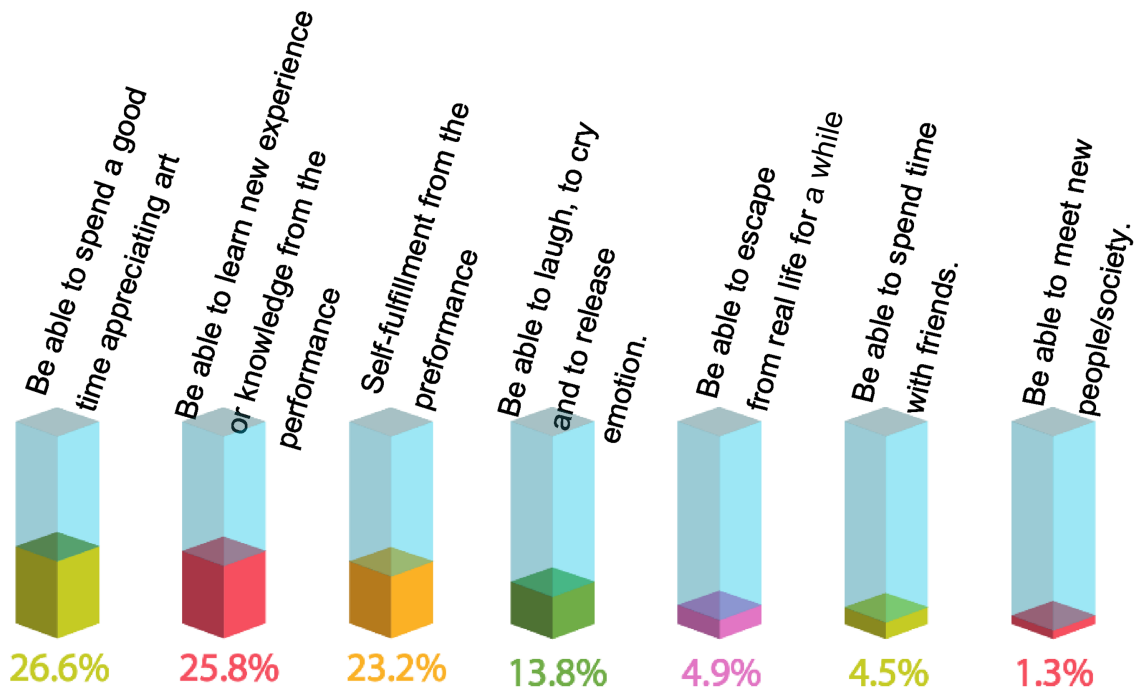

FIGURE 5 The main expectations of audiences for the performances they attend

\section{2 $\quad$ Artist Voices}

From the in-depth interviews of 27 professional representatives in the performing arts and two focus groups with young theatre companies, the key constraints they mention for building or increasing their audiences seem to be as the following.

First, interview data shows that most non-mainstream theatre companies in Thailand are artist-run organizations. They serve as platforms to show the artists' thought, stories, and passions. Their work is identified by their taking a product-led approach, where artistic concerns for creative work outweigh 
administrative or management work. The interviewed arts organizations also believe that "marketing" is a tool for commercial arts organizations, which implies viewing audiences as customers, so they often downplay its importance.

Secondly, limitations due to venue space and location are significant problems for most organizations. Most interviewed organizations complained about the following items: they do not own their own space or building, or their venues are difficult to access or located far from familiar or accessible places, or they have limited seating or the small venue has an inhospitable atmosphere. The lack of company ownership or access to a space or building naturally affects the financial side of the arts organizations' work, like the rental costs of rehearsal space and theatre spaces for performing their work. The uncertain and shifting locations of the company or its inconvenient location (far away from city center, with no parking lot and no public transport) make it difficult for audiences to attend performances or support the company's work. In addition, the venue's atmosphere is also mentioned by groups of art space administrators, since many non-mainstream venues usually have a less than hospitable atmosphere that may negatively affect the experience of new audiences at performances.

Another finding from the interviews relates to communication issues. Most companies note that the role and value of traditional mass media (newspapers, TV, radio, etc.) has decreased in promoting their work. While this has prompted the companies to increase their use digital media to compensate for this loss for their PR activities, the use of digital media has its pros and cons. On the one hand, distributing digital PR materials through social media and the internet can save a lot of costs once spent on printing and publication. What's more, news releases and information can be updated in a more timely way or altered as needed. Although posting information on Facebook seems free, the company's ғв page can only be seen by those who follow it. This means that their free posting may not reach enough FB users beyond their followers. Some electronic systems force them to pay more for "post boosting" charges.

Finally, audiences can create problems which affect how organizations run their art spaces, sometimes with drastic consequences. Some companies try to add value to their venues by offering services or perks to their audiences beyond just performances. Yet when they do this, some of their patrons may behave in questionable ways, thus damaging the viability of the art spaces. Some audiences seek complimentary tickets rather than buying them, since they see getting a free or invited ticket as a sign of their prestige or privilege over others. Also, using venue facilities for non-theater purposes can have unexpected effects on the organizations. For example, one art space informed 
audiences that they had negotiated a deal with a nearby hotel to allow audiences attending art events at their venue to use the hotel's parking space for a cheap parking fee during performances, which were normally held on weekday evenings or on weekends. Some audiences tried to take advantage of this service by parking their car at noon during the weekday and then trying to present themselves as art space patrons who should receive a discount parking fee from the hotel later that night after the performance ended. This led the hotel to end the deal it had with that art space, so it could no longer offer convenient parking to its patrons. Similar problems with ad hoc arrangements could be mentioned for other art spaces.

Key implications from this preliminary research could benefits theatre and dance companies, arts spaces, cultural organizations, and cultural policymakers. Most importantly, data from both audiences and artists suggest that the lack of two-way communication between them is a main constraint on audience building for theatre and dance organizations in Thailand. This finding confirms the researcher's hypothesis and aligns with previous studies discussed in the literature review. Understanding the needs, desires, and motivations of those attending arts events will help arts organizations to strengthen durable relationships with their audiences (Hill et al., 2003; Mcintyre 2009). Taking an audience-centered approach derives from investigating the barriers that keep people from attending arts events. By doing so, it seeks to cultivate ways to broaden and enrich each audience member's experience of the arts (Maitland 2000). Audience development in Thailand should be systematically planned and carefully managed by theatre and dance organizations who understand their audiences better, rather than haphazardly hope that audiences will come to performances and become theatre goers by chance. This would benefit both the arts organizations and their audiences.

Arts organizations often view audience development as a cost more than as an investment, and sometimes even see it as another word for short term publicity (Walmsley 2011). But artists are part of cultural ecosystems which include audiences as an essential part. As such, artists need to systematically seek ways to include audiences in the thinking, planning and design of their activities. This type of audience development work is no less important than the artistic work itself and integral to their unique cultural ecology. Since finances and uncertain funding remain crucial issues for Thailand's non-mainstream contemporary theatre and dance organizations, however, most discussion focus 
on the problems of lacking company ownership, the difficult of accessing venues to rehearse and perform, and the limited seating capacity. This is due to the very tight budgets artists have for their projects. Since productions are almost always done on a low budget, most of their publicity tends to rely on free channels like social media, with little consideration of the purpose or effectiveness of such advertising. Their challenging financial situation mirrors the realworld experiences of these non-mainstream theatre and dance organizations, and keeps them from addressing the key question of how best to develop audiences for their work. The researcher's interviews show the performing artists clearly understand that it is important to build and develop their audiences, but due to their lack of sustained funding and constant budgetary constraints, audience development is less than a top priority item for Thailand's non-mainstream theater and dance groups.

To solve problems tied to audience building and developing it, it is crucial to give holistic consideration of the Thai contemporary arts ecology. This will foster stronger interrelations between artists and audiences at both the operational and policy levels. Further such work can be started from the micro level. Arts organizations can slowly pay more attention to audiences and learn more about audience building and development and include it as a basic part of their thinking and planning. These findings likewise emphasize the importance of arts administrator's know-how to help performing arts organizations run more effectively and efficiently. For this to work, however, more attention to these issues by from government or public cultural agencies is also essential. They could work with cultural organizations and other groups interested by providing special training sessions for arts organizations in audience development.

These preliminary research findings have shown how understanding the multilayered Thai contemporary theatre and dance ecosystem could help to better plan and advocate for audience development. To suit the Thai performance environment, blending appropriate current ideas and theories with Thai approaches to audience is necessary, developing appropriate and sustainable hybrid cultural ecologies. There is also an urgent need to systematically collect primary information and statistical data about contemporary theatre and dance companies in Thailand, which has been incomplete and sporadic up to this point. Basic survey and research are therefore needed in this area to improve the situation.

\section{Acknowledgements}

This study is part of an umbrella project "Performance Research:Doing Creative Research in Contemporary Thai Performing Arts" run by Professor Pornrat Damrhung (a TRF Senior Scholar) supported by the Thailand Research Fund, 
Senior Research Scholar Fund 2016 - 2019 (RTA 5980o10). I deeply thank Dr. Pornrat Damrhung and Dr. Lowell Skar for their kind academic support and helpful suggestion on this research. I would also like to thank Sodsai Pantoomkomol Centre for Dramatic Arts, Department of Dramatic Arts, Faculty of Arts, Chulalongkorn University and LIFE Theatre as an audience questionnaire survey venue. Last but not least, I sincerely thank all interviewees; Theatre and dance companies, performing arts spaces and independent artists/producer for their time to share their confidential information and fruitful discussion. I also wish to thank the two anonymous reviewers of an earlier version of this paper who provided important questions and suggestions, leading to significant improvements in the paper printed here.

\section{References}

Arts Council England. 2018. Arts Council National Lottery Project Grants: Audience Development and Marketing. London: Arts Council England https://www. artscouncil.org.uk/sites/default/files/downloadfile/Information_sheets_Audience_ development_marketing_Project_grants_170518.pdf.

Bamford, Anne, and Michael Wimmer. 2012. Audience Building and the Future Creative Europe Programme. EU: European Expert Network on Culture. http://cedslovenia. eu/wp-content/uploads/2015/og/audience-building-final-report.pdf.

Bollo, Alessandro, Christina Da Milano, Alessandra Gariboldi, and Chris Torch. 2017. Selected Literature Review: Study on Audience Development - How to Place Audiences at the Centre of Cultural Organisations. Brussels: European Commission. http://engageaudiences.eu/download/?filename=http://engageaudiences.eu/ files/2016/o2/Engageaudiences_Literature-review.pdf.

Hill, Liz, Catherin O'Sullivan, and Terry O'Sullivan. 2003. Creative Arts Marketing. New York: Routledge.

Kamsorn, Orapin. 2006. Kanrap kansep lae kanboriphok ngansinlapa (Arts Reception, Appreciation, Consumption). Bangkok: Chommanard. (In Thai).

Maitland, Heather. 2000. A Guide to Audience Development. London: Arts Council of England.

Mcintyre, Morris Hargraves. 20o9. Strategic Marketing and Audience Development for Cultural Organisations. Manchester: Morris Hargreaves Mcintyre.

Thailand, Office of Contemporary Art and Culture, Princess Maha Chakri Sirindhorn Anthropology Centre, and College of Music, Mahidol University. 2014. Performing Arts Venues in Thailand (ho kan sadaeng nai prathet thai). Bangkok: Yin Yang. (In Thai).

Walmsley, Ben, ed. 2011. Key Issues in the Arts and Entertainment Industry. Oxford: Goodfellow. 